\title{
Coping With Cancer: Case Studies on the Effects of Learning About Near-Death Experiences
}

\author{
Ryan D. Foster, PhD, Lauren Maxwell, MS, \\ and William E. Butler, MS \\ Marymount University
}

\begin{abstract}
People diagnosed with cancer frequently report deleterious psychological experiences because of their diagnosis and subsequent medical treatment. One particularly helpful coping strategy reported by cancer patients is psychoeducation on spiritual topics. Anecdotally, cancer survivors reported that psychoeducation about near-death experiences (NDEs) has been a source of great comfort. In this article, we present two case studies on cancer survivors who reported that learning about NDEs helped them cope with cancer successfully by enabling them to face with greater peace both ongoing medical treatment and a potential for death.
\end{abstract}

KEYWORDS: near-death experience, transpersonal, cancer support, psychoeducation, healthcare professionals

Worldwide, cancer is one of the most frequently diagnosed illnesses, with an estimated 14 million new cases diagnosed annually (World Health Organization, 2018). It is imperative that counselors possess knowledge of the long-term physical and psychosocial effects cancer can have on cancer patients and survivors due to the likelihood that

\footnotetext{
Ryan D. Foster, PhD, LPC-S, NCC, CHST, was, at the time of preparing this article, Assistant Professor in the Department of Counseling, School of Education and Human Services, Marymount University in Arlington, VA. He is now Associate Professor in the Department of Counseling, College of Health Sciences and Human Services, Tarleton State University-Fort Worth in Fort Worth, TX. Lauren Maxwell, MS, LPC, and William E. Butler, MS, LPC, were, at the time of preparing this article, master's students in the Department of Counseling, School of Education and Human Services, Marymount University in Arlington, VA. They are now counselors in private practice in Arlington, VA. Correspondence regarding this article should be sent to Dr. Foster at Tarleton State University, 10850 Texan Rider Drive, Fort Worth, TX 76036; email: rdfoster@tarleton.edu.
} 
counselors will have clients who are either cancer patients or survivors (Bennett et al., 2010). Cancer patients and survivors experience a significant amount of emotional, physical, relational, and spiritual distress throughout their coping processes, and may experience feelings of anger, fear, anxiety, depression, loneliness, and guilt at various times throughout the treatment process (National Cancer Institute, 2018; Sadler-Gerhardt et al., 2010). Because cancer patients and survivors often struggle to cope with their diagnoses, effective therapeutic interventions, such as counseling and psychoeducation, can be important adjuncts to medical treatment in increasing coping abilities, quality of life, and overall wellbeing (Badger et al., 2013; Pearce et al., 2012).

Some recent studies support the notion that psychoeducation and counseling can be helpful to cancer patients and survivors. Psychoeducation in these studies consisted of health and psychological education regarding cancer diagnoses, stress management techniques and coping skills, and strategies for assimilating to life in remission. Psychoeducation was administered in a variety of formats, including telephone calls, videos, and counseling and support groups. Bredal et al. (2014) found that psychoeducational approaches focused on understanding and coping with cancer diagnoses that were delivered in a hospital group setting were effective in aiding cancer patients to understand and cope with their diagnoses. Similarly, Badger et al. (2014) found that psychoeducational interventions focusing on mood and affect management, emotional expression, interpersonal communication and relationships, social support, and cancer information and administered via telephone led to an increase in quality of life for breast cancer patients struggling with their diagnoses. Another study examined the effects of psychoeducation that focused on topics including coping with the diagnosis, recovering from surgery, understanding adjuvant therapy, and pursuing ongoing recovery (Sherman et al., 2012). Psychoeducation was administered through videotapes and telephone counseling, and results revealed that wellbeing increased among women diagnosed with early-stage breast cancer.

As with cancer patients, once physicians have declared remission status, survivors of cancer often experience psychosocial, psychological, and relational difficulties as they transition back to their everyday lives (Shannonhouse et al., 2014). After conducting extensive interviews with breast cancer survivors, Sadler-Gerhardt et al. (2010) found that social support and psychoeducation focusing on remission 
and coping with life after cancer would have been the most beneficial form of support for survivors during and after their cancer treatment. In addition, Jones et al. (2013) reported that psychoeducation focused on nursing, treatment options, physical and psychological side effects, physiotherapy, nutrition, and occupational therapy was clinically effective in helping women who were at the end of breast cancer treatment to transition back to their everyday routines. Moreover, Shannonhouse et al. (2014) found that pairing experiential activities with psychoeducation that addressed topics such as medical management, sexuality, spirituality, emotional health, creativity, physical activity, and nutrition, increased cancer survivors' coping skills and decreased relational and social distress.

Relatedly, upon conducting interviews with cancer patients, Vonarx (2015) discovered that cancer patients engaged in psychoeducational activities such as reading books about spirituality and healing as ways to cope with their cancer diagnoses. In addition to social and psychological needs, most cancer patients have spiritual needs, and spirituality often plays a critical role in maintaining cancer patient health and well-being during and after treatment (Alcorn, Balboni, Prigerson, Reynolds, Phelps, Wright, Block, Peteet, Kachnic, \& Balboni, 2010; Pearce et al., 2012; Winkelman, Lauderdale, Balboni, Phelps, Peteet, Block, Kachnic, VanderWeele, \& Balboni, 2011). Delgado-Guay, Hui, Parsons, Govan, De la Cruz, Thorney, and Bruera (2011) found that $98 \%$ of 91 advanced cancer patients considered spirituality to be an important part of their coping processes and that spiritual coping served as a source of comfort and strength (Delgado-Guay et al., 2011). Although research supports a broader concept of spirituality as a helpful source of coping, it may be that learning about psychospiritual experiences could add support to cancer patients or survivors, too.

\section{Research on NDE Psychoeducation}

Near-death experiences (NDEs) are a type of psychospiritual experience. Greyson (2006) discussed exhaustively the relationship between spirituality and NDEs. He concluded that among the many explanatory models of NDEs, physiological models alone could not explain every aspect of NDEs. Especially noteworthy to Greyson were mystical, transcendental, paranormal, and life-altering elements of NDEs, including but not limited to changes in spiritual beliefs or practices. Given the relationship between NDEs and spirituality, it may 
be that learning about NDEs could be helpful to cancer patients or survivors in similar ways that NDE psychoeducation has been helpful to other populations.

For example, Foster and Holden (2014) found that learning about NDEs had a positive effect on grief, a result that other investigators had observed anecdotally (Horacek, 1997; McDonagh, 2004). In a quantitative study of the effects of a bereavement support group model that included a heavy focus on providing psychoeducational videos on NDEs had on adults' grief, Foster and Holden (2014) found that participants had significant decreases in the areas of bereavement-related panic behavior, blame and anger, and detachment, and significant increases in personal growth. Similarly, Winkler (2003) witnessed reduced suicidal ideation in therapy clients as a result of reading NDEr accounts, and Sullivan (1984) even discussed that learning about NDEs provided "supportive preparation for those facing combat" (p. 151).

Anecdotal data have indicated that learning about NDEs may be helpful to patients who may be facing death. Vinter (1994) described his experiences as a hospice nurse. He related two informal interactions he had with patients who were facing death and suggested several comforting effects that learning about NDEs on terminally ill patients could have in hospice settings. Additionally, Deborah Drumm's (1992) letter to the Journal of Near-Death Studies editor underscored her solace after learning about NDEs. Deborah was diagnosed with breast cancer, and after surviving, she described healing experiences resulting from reading narratives of near-death experiencers (NDErs):

I am stronger and more confident than I was before my illness, because I have finally dealt with my fear of death. . . [NDE accounts] give peace of mind and renewed purpose, and allow life to move ahead. (p. 69)

Although research indicates that psychoeducation and support for cancer patients and survivors' spiritual needs is associated with an increased quality of care and improved coping abilities, several studies have documented deficits in spiritual care provision and psychoeducation for cancer patients and survivors (Delgado-Guay et al., 2011; Pearce et al., 2012; Winkelman et al., 2011). Evidence that supports the use of psychoeducational material on NDEs with a variety of populations has emerged in the last few decades. In addition, anecdotal accounts indicate support for the use of NDE psychoeducation with cancer patients and survivors. Therefore, in this study we examined 
the effects of learning about NDEs on two non-NDEr cancer survivors' coping processes before, during, and after medical treatment.

\section{Method}

Initially, I (Foster) received an unsolicited email from a cancer survivor who indicated that she had learned about NDEs when she was a cancer patient and recently found an article that I authored. She also indicated that she had a friend who had a similar experience. She asked if I would be interested in talking with them further about their experiences due to their interest in furthering research understanding of learning about NDEs. I told her that I would have to obtain Marymount University Institutional Review Board (IRB) approval, after which I contacted the potential participants and assessed their current interest in engaging in an interview with one of my research assistants. They both agreed verbally, and I mailed each of them an informed consent form along with a stamped return envelope. I quickly received the signed informed consent forms from them.

Subsequently, I invited and trained two research assistants (RAs), who were master's-level students in a clinical mental health counseling program at the time of this study, to participate in this project. Each RA contacted one of the participants to schedule an in-person interview. RAs used a semi-structured interview format with each participant (see Appendix). Both RAs video-recorded the interviews and transcribed them, and I observed the videos and read the transcripts to ensure each RA adhered to principles of effective qualitative research interviewing. Following are summaries of each interviewin which we changed some details as well as names of participants to ensure confidentiality.

\section{The Case of Susan}

At the time of her interview, Susan was a 47-year-old White female with a graduate degree. Susan was diagnosed with thyroid cancer in February of 1994 at the age of 25 and underwent a thyroidectomy in 1994 and a modified neck dissection in 1995. Before her initial cancer treatment, Susan was unfamiliar with NDEs and experienced both shock and sadness after receiving her first cancer diagnosis: "My first diagnosis, you know, of course that's shocking, and you go, at least for me, you have that process of, you know, first, you cry, then you are sad and question, 'Why me?" 
In 1995, Susan underwent a scan to check for further cancer growth; she was relieved to hear that the scan was clear. Two days later, Susan received a phone call relaying the message that the phone call she had received was inaccurate; her scan was, in fact, not clear, and she would have to undergo further scans to determine next steps. Susan found herself facing yet another surgery, and it needed to occur immediately. Susan felt devastated, and she begun to lose faith in the medical system she once trusted.

Susan stated that she felt lost and longed for a sense of peace and an end to her emotional pain. Shortly thereafter, Susan received that sense of peace through what Susan called a "spiritual encounter." As she was going to sleep one night, Susan noticed a figure at the foot of her bed. The figure consisted of shades of black, grey, and white, and was floating near Susan's bed. The figure then floated up toward her face. The figure had a powerful presence, and Susan began to feel intense heat, light, and a sense of peace:

The heat is amazing. And the peace is amazing. I've never, ever in my life felt that, ever. And it just, it radiated from the center of my chest outwards and downwards and, the most calming, most peaceful, amazing experience. Never had anything like that, ever. But it was very calming, the peace, the feeling, and I think that has profoundly changed me. It has helped me through every episode that I've had. I think it's made me more at peace with mortality.

Susan reported that the few people she told about her spiritual encounter responded mostly with skepticism.

The first time Susan remembered hearing about NDEs was on a television talk show. The narratives Susan heard on the talk show largely resonated with her experiences during her spiritual encounter. Later, she found herself reading books about NDEs, which provided a sense of validation for which Susan was longing and a sense of comfort surrounding her experience of cancer. What resonated most with Susan when learning about NDEs was a sense of peace and the light that others described in their accounts. Susan found that books were the most helpful resource in learning about NDEs, particularly Embraced by the Light by Bettie J. Eadie and Curtis Taylor (1992). Reading these books helped foster a sense of peace for which Susan longed: "It's given me comfort in knowing that when people move from this life to the next life, you know, it's very peaceful. I mean that feeling alone ... whether I lived or died, I was at peace."

Susan was diagnosed with cancer multiple times during the next 10 
years and underwent more surgeries beginning in 1998. Susan faced her subsequent cancer diagnoses and surgeries with increased determination and decreased feelings of shock and sadness.

\begin{abstract}
You-kind of - get your mind around it—hands around it, whatever you want to say-and say, "Okay, game on, let's go." You have that emotional process, so, I had that emotional process pretty much for each one, although, as I went through each time, the emotional ding, it became less and less.
\end{abstract}

Although Susan was never formally declared to be in remission, she has been cancer-free since 2008. When her husband was diagnosed with cancer in 2007, Susan noted that her own experiences and learning about NDEs helped her cope and feel at peace throughout his cancer treatment. Susan's husband is now in remission, and together, they mentor families who are battling cancer themselves. In mentoring other families, Susan hopes to instill a similar sense of peace to that which she experienced through her own spiritual encounter and learning about NDEs. When asked if learning about NDEs had affected her cancer treatment and remission process, Susan replied: "To me, that answer is clearly, yes. Without a doubt."

When asked if and how learning about NDEs affected her ability to cope with her cancer diagnosis and treatment, Susan replied: "It brought me a lot more peace. Just peace, it's just peace in everything and, whether I lived or died, I was at peace." Learning about NDEs not only changed the way Susan coped with both her and her husband's cancer treatment processes, but also affected the way she perceived other trying events in her life, enhancing her ability to cope with them as well.

\title{
The Case of Amelia
}

At the time of her interview, Amelia was a 48-year-old White female with a master's degree in fine arts. Before learning about NDEs, Amelia believed that death was painful and that it would be the end of her existence, which was daunting for her to ponder. Amelia first learned about NDEs at 25-years-old from a book she received from a friend, Susan, called Embraced by the Light by Betty Eadie and Curtis Taylor (1992). Amelia reported that she found this book fascinating, although she admitted initially oscillating between a sense of fascination and malarkey. Around the same time, Amelia also reported reading Raymond Moody's Life After Life (1975) to learn more about NDEs. Com- 
monalities that she understood about NDEs before her cancer diagnosis were the atmosphere of love; out-of-body experiences; no pain; warmth; traveling to, into, or through a tunnel of light; and having a choice to stay or go back to the physical realm. She also understood that when people make the decision to stay, they cannot go back. Additionally, she believed that after an NDE, people change profoundly and have an enhanced sense of loving and caring for others.

Amelia went for a routine mammogram in March of 2012. Approximately two weeks after a biopsy, her physician diagnosed her with breast cancer. Amelia subsequently went through 20 weeks of chemotherapy treatment starting in June of 2012: "Since I was triple negative [the cancer did not respond to progesterone, estrogen, or progestin 2], they had me do the works. I had bilateral mastectomies."

Amelia reported a family history in which cancer led to the deaths of four relatives. During the first two weeks after her diagnosis, she experienced mild panic attacks because of the trauma of her diagnosis from dealing with the emotional aspects of preparing for the possibility of death along with scheduling surgeries, MRIs, ultrasounds, biopsies, and physician interviews.

When Amelia was 12 years old, she had been diagnosed with panic disorder, and in her early twenties she began a medication regimen for panic attacks. Her cancer diagnosis caused her deep distress, and after receiving her diagnosis her panic attacks were harder for her to control. After the first two weeks of the breast cancer diagnosis, she began to re-read books about NDEs and reported that researching NDEs took the panic attacks away. Amelia further reported that she liked to think ahead and be prepared; when she received her breast cancer diagnosis, based on her family history of breast cancer and the uncertainty of living or dying, she immediately turned to learning more about NDEs to alleviate potentially her fear and uncertainty. When asked how learning about NDEs affected her ability to cope with her treatment, Amelia responded:

So after I was diagnosed, I picked up one of the near-death experiences books again just for reassurance. I think it just took a lot of the panic out. Because when I was having those dark panicky feelings, I could go back and say, "It's going to be okay."

Amelia considered herself a spiritual person who has been on a spiritual journey all her life. Amelia stated that she started this spiritual journey before she was diagnosed with cancer. She described her spiritual journey as going to a Lutheran church and bible studies but did 
not find comfort in these activities. At one point in time, she started a spiritual book club where people of different beliefs could talk about their spirituality. In the remission phase of the cancer diagnosis, she said books about NDEs bought her peace, and she realized that every life has a purpose.

Because of her lifelong spiritual journey, NDEs seemed more authentic to Amelia than anything else to which she exposed herself before being diagnosed with breast cancer. Thus, NDE information was a source of comfort and peace for Amelia after her initial cancer diagnosis: "I can believe it [NDEs] because it makes sense. I can't believe that this one religion is the right way ... I guess it [NDEs] resonates with my whole initial belief that we are all praying to the same God."

Amelia stated that before receiving the cancer diagnosis, she understood NDEs intellectually. As she went through her cancer experience, she claimed that she experienced love because she confronted the end of her life and started to understand what was important in life. Amelia became more grateful for everything that she had: "Before the whole experience [cancer diagnosis], I was obsessed with finding the perfect rug for my living room, and that seemed very important at the time. Now I look back and I am like, are you kidding?" Amelia reported that she was both scientific and spiritual in her approach to understanding NDEs. A particularly convincing factor regarding NDEs was veridical perception, in which NDErs report having perceived things during their NDEs that, based on the position and condition of their physical bodies, they should not have been able to perceive-but that, nevertheless were subsequently verified as accurate. She mentioned, for example, that after they had been clinically dead, NDErs could describe conversations that were happening in a different room, which made NDEs believable to her.

Amelia reported that she found many aspects of NDEs helpful in coping with her cancer process. For example, she stated that NDEs confirmed for her a belief in an afterlife. Additionally, she affirmed her belief that death is peaceful, that she would see loved ones again, that there would be a guide to help her enter an afterlife, and that she can communicate in some way to with loved ones who are now discarnates and know what to do in the death transition process. Characteristics of pleasurable NDEs that she read about, such as love, joy, and peace, were also a comfort to Amelia. However, she also stated that reading about distressing NDEs was unhelpful to her, because she believed that death would lead to peace rather than terror.

Amelia noted that she entered remission by December of 2012. At 
the time of her participation in our interview, she was working on her second master's degree in social work and aspired to work with hospice patients. Amelia stated that hospital chaplains should expose anyone going through cancer treatment, or any terminal illness, to NDE information. She asserted: "I think it would be helpful for them [hospital chaplains] to be able to talk to people about it and just like they would talk about Christianity, or Judaism, or whatever helps."

\section{Limitations}

A clear limitation in this study is the nature of case study research. Although Amelia's and Susan's narratives appear to comprise important cases that contribute to a better understanding of influences of NDE psychoeducation, researchers cannot generalize the results to other cancer patients or survivors. In addition, despite our best efforts to ensure the interviews were completed according to a defined protocol, the interview process may have been impacted by differences in personalities of the RAs and other extraneous variables such as nonverbal communication style. The interviews were semi-structured; thus, RAs had freedom to ask follow-up questions based on data gathered from each participant.

Furthermore, it should be noted that Susan's coping was compounded by her experience of what she called a "spiritual encounter," in addition to learning about NDEs. Similarly, Susan was engaged in a spiritual book club, and any non-NDE books she read may have had a positive effect on her wellbeing. In both cases, it is nearly impossible to separate the effects of other experiences from the impact of NDE learnings. Finally, it is important to note that Amelia made unsolicited contact with the first author; therefore, caution should be exercised when interpreting any findings of this study due to the selfselected nature of participant recruitment.

\section{Implications and Conclusions}

When supporting clients diagnosed with cancer, counselors need to have an array of methods to assist in encouraging psychological wellbeing. Spirituality seems to be a meaningful part of psychological wellbeing for clients struggling with cancer (Alcorn et al., 2010; Pearce et al., 2012; Winkelman et al., 2011). Prior research demonstrated that one of these supportive mechanisms is psychoeducation, particularly on spiritual topics (Vonarx, 2015), and-anecdotally-even more 
specifically on NDEs (Drumm, 1992; Vinter, 1994). Despite the limitations of the current inquiry, both Susan and Amelia's narratives add qualitative evidence underscoring the potential value of using NDE educational materials to assist cancer patients and survivors. Amelia and Susan emphasized clearly that prior knowledge of and learning more about NDEs positively influenced their psychological and spiritual health.

However, we want to signal caution in any broader interpretation of our findings from this case study research. Case study research can be compelling, as Susan and Amelia's narratives appear, but also it can be misleading. This study was not designed as a formal qualitative research study; therefore, any conclusions should be viewed through a critical lens. Notwithstanding these cautions, these cases warrant further exploration in practice and research.

Mental health counselors, medical social workers, nurses, physicians, pastoral counselors, and hospital chaplains can benefit from this study by understanding that providing cancer patients with NDE materials may help improve coping strategies. Foster, James, and Holden (2009) highlighted the important roles that these professionals have in supporting non-NDErs in hospital settings, and the results of this study adds to that suggestion. These professionals would do well by their clients and patients by having a resource list of books and other media on NDEs to offer their clientele. Foster et al. also suggested that professionals who interact with patients in medical settings should have some formal training to increase their knowledge of NDEs. The results of these case studies also support a broader evidence base for the use of psychoeducational NDE resources with other non-NDEr client populations to assist in mental health and wellness (e.g., Foster \& Holden, 2014; Horacek, 1997; McDonagh, 2004; Sullivan, 1984; Winkler, 2003).

Furthermore, NDE researchers may want to consider implications as a result of this study. There is a need to gather more extensive qualitative and quantitative data examining the impact of NDE psychoeducation on people diagnosed with cancer. Researchers could replicate the semi-structured interview used in this study (see Appendix) in qualitative studies with a larger sample in order to analyze emerging themes formally, perhaps resulting in a more nuanced understanding of participant experiences. In addition, adapting this semi-structured interview for use in a survey study would enable analysis of quantitative trends and patterns. It is our hope that future researchers will take the opportunity to expand the groundwork laid here to establish 
evidence for sound approaches that mental health, medical, and pastoral practitioners can use with patients diagnosed with cancer.

\section{References}

Alcorn, S. R., Balboni, M. J., Prigerson, H. G., Reynolds, A., Phelps, A. C., Wright, A. A., Block, S. D., Peteet, J. R., Kachnic, L. A., \& Balboni, T. A. (2010). "If God wanted me yesterday, I wouldn't be here today": Religious and spiritual themes in patients' experiences of advanced cancer. Journal of Palliative Medicine, 13(5), 581-588. https://doi.org/10.1089/jpm.2009.0343

Badger, T. A., Segrin, C., Hepworth, J. T., Pasvogel, A., Weihs, K., \& Lopez, A. M. (2013). Telephone-delivered health education and interpersonal counseling improve quality of life for Latinas with breast cancer and their supportive partners. Psycho-Oncology, 22, 1035-1042. https://doi.org/10.1002/pon.3101

Bennett, J. A., Cameron, L. D., Brown, P. M., Whitehead, L. C., Porter, D., \& Ottaway-Parkes, T. (2010). Time since diagnosis as a predictor of symptoms, depression, cognition, social concerns, perceived benefits, and overall health in cancer survivors. Oncology Nursing Forum, 37, 331-338. https://doi .org/10.1188/10.onf.331-338

Bredal, I. S., Kåresen, R., Smeby, N. A., Randi, E., Sørensen, E. M., Amundsen, M., Aas, H., \& Ekeberg, Ø. (2014). Effects of a psychoeducational versus a support group intervention in patients with early-stage breast cancer: Results of a randomized controlled trial. Cancer Nursing, 37(3), 198-207. https://doi .org/10.1097/NCC.0b013e31829879a3

Delgado-Guay, M. O., Hui, D., Parsons, H. A., Govan, K., De la Cruz, M., Thorney, S., \& Bruera, E. (2011). Spirituality, religiosity, and spiritual pain in advanced cancer patients. Journal of Pain and Symptom Management, 41(6), 986-994. https://doi.org/10.1016/j.jpainsymman.2010.09.017

Drumm, D. L. (1992). Near-death accounts as therapy [letter]. Journal of NearDeath Studies, 11, 67-70. https://doi.org/10.17514/JNDS-1992-11-1-p67-70.

Eadie, B. J., \& Taylor, C. (1992). Embraced by the light. Gold Leaf.

Foster, R. D., \& Holden, J. M. (2014). Eternal connection: An exploratory study of the effects of learning about near-death experiences on adult grief. Journal of Loss and Trauma, 19, 40-55. https://doi.org/10.1080/15325024.2012.735189

Foster, R. D., James, D., \& Holden, J. M. (2009). Practical applications of research on near-death experiences. In J. M. Holden, B. Greyson, \& D. James (Eds.), The handbook of near-death experiences: Thirty years of investigation (pp. 235-258). Praeger/ABC-CLIO.

Horacek, B. J. (1997). Amazing grace: The healing effects of near-death experiences on those dying and grieving. Journal of Near-Death Studies, 16, 149161. https://doi.org/10.17514/JNDS-1997-16-2-p149-161.

Jones, J. M., Cheng, T., Jackman, M., Walton, T., Haines, S., Rodin, G., \& Catton, P. (2013). Getting back on track: Evaluation of a brief group psychoeducation intervention for women completing primary treatment for breast cancer. Psycho-Oncology, 22, 117-124. https://doi.org/10.1002/pon.2060

McDonagh, J. (2004). Introducing near-death research findings into psychotherapy. Journal of Near-Death Studies, 22, 269-273. https://doi.org/10.17514/ JNDS-2004-22-4-p269-273. 
Moody, R. A., Jr. (1975). Life after life. Mockingbird.

National Cancer Institute (2018, August 20). Feelings and cancer. https://www .cancer.gov/about-cancer/coping/feelings

Pearce, M. I., Coan, A. D., Herndon II, J. E., Koenig, H. G., \& Abernathy, A. P. (2012). Unmet spiritual care needs impact emotional and spiritual well-being in advanced cancer patients. Support Care Center, 20, 2269-2276. https://doi .org/10.1007/s00520-011-1335-1

Sadler-Gerhardt, C. J., Reynolds, C. A., Britton, P. J., \& Kruse, S. D. (2010). Woman breast cancer survivors: Stories of change and meaning. Journal of Mental Health Counseling, 32, 265-282. https://doi.org/10.17744/mehc.32.3 .q14777j84kx3285x

Shannonhouse, L., Myers, J., Barden, S., Clarke, P., Weimann, R., Forti, A., Moore-Painter, T., Knutson, T. \& Porter, M. (2014). Finding your new normal: Outcomes of a wellness-oriented psychoeducational support group for cancer survivors. Journal for Specialists in Group Work, 39(1), 3-28. https://doi.org/ 10.1080/01933922.2013.863257

Sherman, D. W., Haber, J., Hoskins, C. N., Budin, W. C., Maislin, G., Shukla, S., Cartwright-Alcarese, F., McSherry, C. B., Feurbach, R., Kowalski, M. O., Rosedale, M., \& Roth, A. (2012). The effects of psychoeducation and telephone counseling on the adjustment of women with early-stage breast cancer. Applied Nursing Research, 25, 3-16. https://doi.org/10.1016/j.apnr.2009.10.003

Sullivan, R. M. (1984). Combat-related near-death experiences: A preliminary investigation. Anabiosis-The Journal for Near-Death Studies, 4, 143-152. https://doi.org/10.17514/JNDS-1984-4-2-p143-152.

Vinter, M. (1994). An insight into the afterlife: Informing patients about near death experiences. Professional Nurse, 10(3), 171-173.

Vonarx, N. (2015). Cancer patients and spiritual experiences: Redefining the self through initiatory ordeals. Palliative and Supportive Care, 13(1), 27-40. https://doi.org/10.1017/S1478951513000175

Winkelman, W. D., Lauderdale, K., Balboni, M. J., Phelps, A. C., Peteet, J. R., Block, S. D., Kachnic, L. A., VanderWeele, T. J., \& Balboni, T. A. (2011). The relationship of spiritual concerns to the quality of life of advanced cancer patients: Preliminary findings. Journal of Palliative Medicine, 14(9), 1022-1028. https://doi.org/10.1089/jpm.2010.0536

Winkler, E. J. (2003). The Elias Project: Using the near-death experience potential in therapy. Journal of Near-Death Studies, 22, 79-82. https://doi .org/10.17514/JNDS-2003-22-2-p79-82.

World Health Organization (2018, September 12). Cancer. https:/www.who.int/ en/news-room/fact-sheets/detail/cancer

\section{Appendix}

NDE Coping With Cancer Semi-Structured Interview

\section{Section 1}

1. What is your sex and gender identity?

2. What is your year of birth?

3. What is your ethnicity? 
4. What is your education level?

5. When were you diagnosed with cancer?

6. When did your cancer treatment take place? For how long?

7. When were you formally considered in remission?

8. What were the circumstances surrounding your cancer diagnosis and treatment?

\section{Section 2}

For the purposes of this interview, a near-death experience is defined as

profound psychological events with transcendental and mystical elements, typically occurring to individuals close to death or in situations of intense physical or emotional danger. These elements include ineffability, a sense that the experience transcends personal ego, and an experience of union with a divine or higher principle.

Near-death experiences include the elements of

(a) cognitive features of time distortion, thought acceleration, a life review and revelation; (b) affective features of peace, joy, cosmic unity and an encounter with light; (c) paranormal features of vivid senses, apparent extrasensory perception and precognitive visions, and an out-of-body experience; and (d) transcendental features of otherworldly encounters with mystical beings, visible spirits, and an uncrossable border.

9. Before your cancer treatment, what did you know about near-death experiences?

10. When did you first learn about NDEs?

11. How did you learn about NDEs?

12. What resources (e.g., specific books, movies, websites) about NDEs were most helpful?

13. What resources were least helpful?

14. What was your initial reaction to learning about NDEs?

15. How did learning about NDEs effect your ability to cope with your cancer diagnosis and/or treatment?

16. What aspects of NDEs did you find most helpful in your coping with cancer process?

17. What aspects of NDEs did you find least helpful in your coping with cancer process?

18. Anything else that you'd like to share? 